\title{
The importance of early developmental neuroscience for research, practice, and policy
}

\author{
Ana Raquel M. Mesquita', Adriana da C. S. Sampaio', and Ana Alexandra C. Osório² \\ 1 Psychological Neuroscience Lab, CIPsi, University of Minho \\ ${ }^{2}$ Developmental Disorders Program and Mackenzie Center for Research in Childhood and Adolescence, \\ Center for Biological and Health Sciences, Mackenzie Presbyterian University
}

\section{Author note}

Ana Raquel M. Mesquita (D) https://orcid.org/00oo-0002-9635-2355

Adriana da C. S. Sampaio (D) https://orcid.org/0ooo-0001-7347-1282

Ana Alexandra C. Osório (D) https://orcid.org/0000-0002-1692-4609

Ana Mesquita and Adriana Sampaio are supported by the Psychology Research Centre (PSI/01662), School of Psychology, University of Minho, through the Portuguese Foundation for Science and Technology (FCT) and the Portuguese State Budget (Ref.: UIDB/PSI/01662/2020). Ana Mesquita is supported by the Portuguese Foundation for Science and Technology (FCT) and the EU through the European Social Fund and the Human Potential Operational Program - IF/00750/2015. Ana Osório is supported by CAPES/PrInt grant no. 88887.310343/2018-00 and CAPES PROEX grant no. 0426/2021, process no. 23038.006837/2021-73.

Correspondence concerning this article should be addressed to Ana R. Mesquita, CIPsi, School of Psychology, University of Minho, Campus de Gualtar, 4710-057 Braga, Portugal. E-mail: ana. mesquita@psi.uminho.pt 
The most intense rhythm of brain maturation in humans occurs in early childhood the period between zero and 5 years of age. Such significant structural or functional development is not observed at any other homologous period throughout the lifespan. From a simple tubular structure in the foetal period (the neural tube), in a few years the brain develops a highly complex cytoarchitecture (Dubois et al., 2021; Ouyang et al., 2019). Its size also increases significantly, with the brain of a 6-year-old having nearly the volume (95\%) of the adult brain (Lenroot \& Giedd, 2006). In addition, early childhood is the most productive period in creating new synapses - for example, reaching 15,000 connections per neuron between 2-3 years of age - twice as many as the amount observed in adults (Huttenlocher, 1979). Brain metabolism also peaks at $200 \%$ of the adult pattern at about 4 years of age (Chugani, 1998). These maturational phenomena are the foundation of a child's physical and mental health, determining longevity and the ability to learn from contextual changes and adapt to them (Cruz et al., 2020; Sampaio \& Lifter, 2014). In turn, these phenomena are influenced by an array of genetic and environmental factors. As described by the National Scientific Council on the Developing Child (2012, p. 1), "experiences 'authorize' genetic instructions to be carried out and shape the formation of the (brain) circuits as they are being constructed". This sentence illustrates how early experiences may be biologically embedded in the development of multiple systems, including long-term impacts on the brain. More specifically, experiences associated with caregiver psychopathology, neglect, poverty, or social exclusion both pre and postnatally have been shown to compromise optimal brain development (McLaughlin et al., 2011). Finally, the early years are an open window of susceptibility to experience, making it a period of heightened sensitivity and plasticity to the effects of both positive and negative biological and psychosocial experiences on the developing brain (Black et al., 2017; Fox et al., 2010), highlighting the need to implement intervention programmes as early as possible.

Recent evidence shows that approximately $43 \%$ of children younger than 5 years living in low or middle-income countries, such as Brazil, are at risk of failing to reach their developmental potential due to extreme poverty and stunting (Black et al., 2017). Indeed, advances in early developmental neuroscience have provided robust evidence on how poverty and other early adverse experiences have long terms effects on brain development and, consequently, on the development of early social, emotional, and cognitive abilities (Luby, 2015; Noble et al., 2015; Shonkoff \& Garner, 2012). These will, in turn, affect health and development prospects throughout the life cycle (Weaver, 2014).

From an economic viewpoint, the studies by James Heckman and his team strongly support the investment in the early years rather than remedial interventions later in development (Heckman, 2008). Their studies were unequivocal in documenting that early intervention programs targeted towards socioeconomically disadvantaged young children are estimated to have high cost-benefit ratios, with no equity-efficiency trade-off - i.e., increasing 
economic efficiency while reducing lifetime inequality -, contrasting with the programs targeted toward later years, usually associated with lower economic efficiency and lower rates of return (Doyle et al., 2009; Heckman, 2008, 2012). Specifically, interventions in infancy have the potential to promote multiple personal and social benefits as well as government savings, such as sustained economic efficiency, reduced delinquency, reduced lifetime inequality, increased opportunities in terms of educational attainment, quality of learning and work productivity, and better developmental outcomes such as improved physical and mental health and decreased mortality and morbidity (IOM/NCR, 2014; Shonkoff, 2010). Recently, evidence pointed to intergenerational gains, with the children of those that directly benefited from these programs in early childhood also presenting better outcomes (Heckman \& Karapakula, 2019). Taken together, the evidence summarised here not only highlights the strategic importance of promoting optimal early childhood development but also the urgency of investing in the scientific study of the brain in this critical period of human development.

The relatively new area of developmental neuroscience is beginning to change the way we think about development in early childhood as well as early childhood development interventions. As separate fields of study come together, we gain more knowledge on how the brain matures, brain-behaviour relationships, and what factors may promote or hinder optimal human development, particularly in more socioeconomically disadvantaged contexts. In turn, developmental neuroscientists must also embrace their responsibility of synthesizing the most up-to-date knowledge, translating it into accessible language, and transferring this evidence-based knowledge from research to policy and practice (Shonkoff \& Bales, 2011). 


\section{References}

Black, M. M., Walker, S. P., Fernald, L. C., Andersen, C. T., DiGirolamo, A. M., Lu, C., McCoy, D. C., Fink, G., Shawar, Y. R., Shiffman, J., Devercelli, A. E., Wodon, Q. T., Vargas-Barón, E., Grantham-McGregor, S., \& Lancet Early Childhood Development Series Steering Committee. (2017). Early childhood development coming of age: Science through the life course. The Lancet, 389(10064), 77-90. https://doi.org/10.1016/S0140-6736(16)31389-7

Chugani, H. T. (1998). A critical period of brain development: Studies of cerebral glucose utilization with PET. Preventive Medicine, 27(2), 184-188. https://doi.org/10.1006/pmed.1998.0274

Cruz, S., Lifter, K., Barros, C., Vieira, R., \& Sampaio, A. (2020). Neural and psychophysiological correlates of social communication development: Evidence from sensory processing, motor, cognitive, language and emotional behavioral milestones across infancy. Applied Neuropsychology Child, 23, 1-20. https://doi.org/10.1080/21622965.2020.1768392

Doyle, O., Harmon, C. P., Heckman, J. J., \& Tremblay, R. E. (2009). Investing in early human development: Timing and economic efficiency. Economics \& Human Biology, 7(1), 1-6. https://doi. org/10.1016/j.ehb.2009.01.002

Dubois, J., Alison, M., Counsell, S. J., Hertz-Pannier, L., Hüppi, P. S., \& Benders, M. J. (2021). MRI of the neonatal brain: A review of methodological challenges and neuroscientific advances. Journal of Magnetic Resonance Imaging, 53(5), 1318-1343. https://doi.org/10.1002/jmri.27192

Heckman, J. J. (2008). Schools, skills, and synapses. Economic Inquiry, 46(3), 289-324. https://doi. org/10.1111/j.1465-7295.2008.00163.x

Heckman, J. J. (2012). Invest in early childhood development: Reduce deficits, strengthen the economy. https://heckmanequation.org/resource/invest-in-early-childhood-development-reduce-deficitsstrengthen-the-economy/

Heckman, J. J., \& Karapakula, G. (2019). Intergenerational and intragenerational externalities of the Perry Preschool Project (No. w25889). National Bureau of Economic Research.

Institute of Medicine (IOM), \& National Research Council (NRC) (2014). The cost of inaction for young children globally: Workshop summary. The National Academies Press. https://doi. org/10.17226/18845

Fox, S. E., Levitt, P., \& Nelson III, C. A. (2010). How the timing and quality of early experiences influence the development of brain architecture. Child development, 81(1), 28-40. https://doi. org/10.1111/j.1467-8624.2009.01380.x

Huttenlocher, P. R. (1979). Synaptic density in human frontal cortex-developmental changes and effects of aging. Brain Research, 163(2), 195-205. https://doi.org/10.1016/00068993(79)90349-4

Lenroot, R. K., \& Giedd, J. N. (2006). Brain development in children and adolescents: Insights from anatomical magnetic resonance imaging. Neuroscience \& Biobehavioral Reviews, 30(6), 718-729. https://doi.org/10.1016/j.neubiorev.2006.06.001

Luby, J. L. (2015). Poverty's most insidious damage: The developing brain. JAMA Pediatrics, 169(9), 810-811. https://doi.org/10.1001/jamapediatrics.2015.1682 
McLaughlin, K. A., Fox, N. A., Zeanah, C. H., \& Nelson, C. A. (2011). Adverse rearing environments and neural development in children: The development of frontal electroencephalogram asymmetry. Biological Psychiatry, 70(11), 1008-1015. https://doi.org/10.1016/j.biopsych.2011.08.006

National Scientific Council on the Developing Child. (2012). The Science of Neglect: The Persistent Absence of Responsive Care Disrupts the Developing Brain: Working Paper No. 12. https://developingchild.harvard.edu/resources/the-science-of-neglect-the-persistent-absence-of-responsive-caredisrupts-the-developing-brain/

Noble, K. G., Houston, S. M., Brito, N. H., Bartsch, H., Kan, E., Kuperman, J. M., Akshoomoff, N. Amaral, D. G., Bloss, C. S., Libiger, O., Schork, N. J., Murray, S. S., Casey, B. B., Chang, L., Ernst, T. M., Frazier, J. A., Gruen, J. R., Kennedy, D. N., Zijl, P. V., ... Sowell, E. R. (2015). Family income, parental education and brain structure in children and adolescents. Nature Neuroscience, 18, 773-78. https://doi.org/10.1038/nn.3983

Ouyang, M., Dubois, J., Yu, Q., Mukherjee, P., \& Huang, H. (2019). Delineation of early brain development from fetuses to infants with diffusion MRI and beyond. Neuroimage, 185, 836-850. https://doi.org/10.1016/j.neuroimage.2018.04.017

Sampaio, A., \& Lifter, K. (2014). Neurosciences of infant mental health development: Recent findings and implications for counseling psychology. Journal of counseling Psychology, 61(4), 513-520. https://doi.org/10.1037/couooooo35

Shonkoff, J. (2010). Building a new biodevelopmental framework to guide the future of early childhood policy. Child Development, 81(1), 357-367. https://doi.org/10.1111/j.1467-8624.2009.01399.x

Shonkoff, J. P., \& Bales, S. N. (2011). Science does not speak for itself: Translating child development research for the public and its policymakers. Child Development, 82(1), 17-32. https://doi. org/10.1111/j.1467-8624.2010.01538.x

Shonkoff, J. P., \& Garner, A. S. (2012). The lifelong effects of early childhood adversity and toxic stress. Pediatrics, 129(1), e232-e246. https://doi.org/10.1542/peds.2011-2663

Weaver, I. C. (2014). Integrating early life experience, gene expression, brain development, and emergent phenotypes: Unraveling the thread of nature via nurture. Advances in Genetics, 86, 277-307. https://doi.org/10.1016/b978-0-12-800222-3.00011-5

Editorial board
Editor-in-chief
Cristiane Silvestre de Paula
Associated editors
Alessandra Gotuzo Seabra
Ana Alexandra Caldas Osório
Luiz Renato Rodrigues Carreiro
Maria Cristina Triguero Veloz Teixeira
Section editors
"Psychological Evaluation"
Alexandre Luiz de Oliveira Serpa
André Luiz de Carvalho Braule Pinto
Luiz Renato Rodrigues Carreiro
Vera Lúcia Esteves Mateus
"Psychology and Education"
Alessandra Gotuzo Seabra
Carlo Schmidt
Regina Basso Zanon

"Social Psychology and
Population's Health"
Enzo Banti Bissoli
Marina Xavier Carpena

"Clinical Psychology"

Carolina Andrea Ziebold Jorquera

Julia Garcia Durand

Natalia Becker

\section{"Human Development"}

Maria Cristina Triguero Veloz Teixeira

Rosane Lowenthal

\section{Technical support}

Maria Fernanda Liuti Bento da Silva

Camila Fragoso Ribeiro
Editorial production

Publishing coordination

Ana Claudia de Mauro

\section{Editorial interns}

Élcio Carvalho

Júlia Lins Reis

Pietro Menezes

\section{Layout designer}

Acqua 